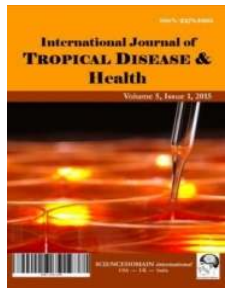

International Journal of TROPICAL DISEASE

\& Health

20(1): 1-10, 2016, Article no.IJTDH.28551

ISSN: 2278-1005, NLM ID: 101632866

SCIENCEDOMAIN international

www.sciencedomain.org

\title{
Modelling the Influence of Covariates of Typhoid Patients at the Tamale Teaching Hospital Using Generalised Linear Models
}

\author{
Alhassan Abdul Latif ${ }^{1^{*}}$, Abukari Alhassan ${ }^{1}$ and Kaku Sagary Nokoe ${ }^{2}$ \\ ${ }^{1}$ Department of Statistics, Faculty of Mathematical Sciences, University for Development Studies, \\ Navrongo, Ghana. \\ ${ }^{2}$ Catholic University of East Africa (CUEA), Lang'ata, P.O.Box 62157-00200, Nairobi, Kenya.
}

\section{Authors' contributions}

This work was carried out in collaboration between all authors. Author AAL worked on the background, methodology, analysis of the data and the literature review. Author AA worked on the interpretation, discussions and the conclusion. Author KSN edited the work. All authors read and agreed on the final manuscript.

Article Information

DOI: $10.9734 / \mathrm{IJTDH} / 2016 / 28551$

Editor(s):

(1) Giuseppe Murdaca, Clinical Immunology Unit, Department of Internal Medicine, University of Genoa, Italy.

Reviewers:

(1) Obiekea Kenneth Nnamdi, Ahmadu Bello University, Zaria, Kaduna, Nigeria.

(2) Prabhaker Mishra, Sanjay Gandhi Post Graduate Institute of Medical Sciences (SGPGIMS), Raebareli Road, Lucknow,

India.

(3) Charbell Miguel Haddad Kury, Medical School of the Municipality of Campos dos Goytcazes, State of Rio de Janeiro, Brazil. Complete Peer review History: http://www.sciencedomain.org/review-history/16673

Original Research Article

Received $25^{\text {th }}$ July 2016 Accepted $22^{\text {nd }}$ September 2016 Published 26 $6^{\text {th }}$ October 2016

\begin{abstract}
Typhoid fever and typhoid perforation has become a major burden and causes a lot of deaths in the world especially in developing countries. This study considered a total of 418 patients diagnosed of Typhoid fever at the Tamale Teaching Hospital covering the period January 2010 to June 2015.

The data was modelled using the Negative binomial regression model to ascertain the duration (days) of admission cases as well as the effect of some covariates. Preliminary analysis revealed children of school going age as the most vulnerable. Further, collinearity diagnostics did not exhibit interaction among the predictors. The results identified cost of treatment, location of patients and outcome of admission as significant contributing covariates.

Based on the results, it was recommended that policy makers should take keen interest on the cost of treatment of typhoid since rising cost of treatment is likely to increase the number of days spent in the hospital thereby putting pressure on hospital facilities.
\end{abstract}


Keywords: Infections; Salmonella; typhoid; morbidity and covariates.

\section{INTRODUCTION}

Typhoid fever is one of the leading causes of morbidity and mortality across the world [1]. Typhoid is caused by a bacterium of the genus Salmonella. Salmonella infection in humans can be categorised into two broad types, that caused by low virulence serotypes of Salmonella enterica which cause food poisoning, and that caused by the high virulence serotypes Salmonella enterica typhi (S. typhi), that causes typhoid, and a group of serovars, known as $S$. Paratyphi A, B and C, which cause Paratyphoid [2]. According to [3] also Typhoid fever is a potentially severe and occasionally lifethreatening febrile illness caused by the bacterium Salmonella enterica serotype Typhi. Paratyphoid fever is a similar illness caused by S. enterica serotype Paratyphi A, B (tartrate negative), or $\mathrm{C}$. Humans are the only host of this latter group of pathogens. S. Typhi is a highly adapted human-specific pathogen [4], and the illness caused by these bacteria is a serious public health concern, particularly in developing countries $[5,6]$.

However, typhoid and paratyphoid fevers are still common in less-industrialized countries, owing to the consumption of unsafe drinking water, inadequate sewage disposal and flooding. The last important outbreak recorded by the World Health Organization (WHO) counted a total of 42,564 cases and 214 deaths (case fatality ratio, $0.5 \%$ ) in the Democratic Republic of Congo from September 2004 to January 2005 [7]. Typhoid fevers are systemic diseases characterized by diarrhea, fever, loss of appetite, headache, malaise, abdominal pain and progressive weakness, prostration, confusion and delirium. When untreated, typhoid fever persists for three weeks to a month; the most common treatment consists of antibiotics such as ampicillin, amoxicillin or ciprofloxacin. Possible complications that can lead to death are intestinal hemorrhage and perforation, kidney failure and peritonitis [8].

"Typhoid Mary," a cook who was closely associated with forty-seven cases and three deaths in New York over 100 years ago [1]. Diagnostic suspicion is based on clinical data complemented by information on travel. For the final diagnosis to be established, the bacteria have to be detected in stool, blood or bone marrow samples, or by the Widal test. There are two vaccines currently recommended by the WHO, both available on the Spanish market. One is the oral Vivotif manufactured with live mutant bacteria of Salmonella typhi Ty21a, and the other is the injectable Typhim which consists of the Vi capsular polysaccharide [9] and [10]. Both are protective against Salmonella typhi infection and are recommended for travellers going to areas where typhoid is endemic. There are several studies that show cross protection against Salmonella paratyphi A and B with Vivotif [11]. In Spain, the primary risk population consists of travellers to the Indian Subcontinent and Africa [12]. Typhoid and paratyphoid fever are important causes of morbidity and mortality and they result in large financial expenditures for the National Health Care System, especially due to hospitalizations [13]. According to the study of [14], drinking unboiled water at home was a significant risk factor in Kamalapur-Dhakar.

A recent estimate found that 22 million new typhoid cases occur each year in the world with some 200,000 of these resulting in death [15], indicating that the global burden of this disease has increased steadily from a previous estimate of 16 million [15]. However, case-fatality rates have decreased remarkably [16]. The highest number of cases ( $>100$ per 100,000 persons/year) and consequent fatalities are believed to occur in South Central and Southeast Asia [1]. Generally, typhoid is endemic in impoverished areas of the world where the provision of safe drinking water and sanitation is inadequate and the quality of life is poor [17]. The best figures available for the global burden of enteric fever support this and suggest that Africa $(50 / 100,000)$ has a far lower burden of disease than Asia $(274 / 100,000)$. Although contaminated food [4,14,18-21], and water [19,22-25] have been identified as the major risk factors for typhoid prevalence. A range of other factors have been reported in different endemic settings such as poor sanitation [26], close contact with typhoid cases or carriers [27], level of education, larger household size, closer location to water bodies [27,28], flooding [29], personal hygiene [22], poor life style [25], and travelling to endemic areas [30]. In addition, climatic variables such as, rainfall, vapour pressure and temperature have an important effect on the transmission and distribution of typhoid infections in human populations [22,31].

Marks et al. [32] also posited that typhoid infection among children below five years was 
high and identified defecating in free range as the main contributing factor in the Agogo community of the Ashanti region of Ghana.

There has been very scanty scientific study on the issue of typhoid fever in the northern Ghana. The issue of key covariates which turn to influence the length of stay of typhoid patients at the hospital is also been neglected in the scanty literature available in Ghana. It is against this background that, this study attempts to model the covariates that influence the length of stay of patients with typhoid fever in the hospital.

\section{MATERIALS AND METHODS}

This comprises of the data management and the study area.

\subsection{Data Management and Sample Size}

The data used in this study was a secondary data from Tamale Teaching Hospital. Tamale Teaching Hospital is located in the capital town of Northern Region-Ghana. Ghana is located in West Africa. It has a total population of over twenty four million people $(24,000,000)$ [33]. The sample size was four hundred and eighteen (418). It covers the period from January 2010 to June 2015. This data was extracted from among other ailments from the District Health Information Management System (DHIMS). Tamale has a total population of $2,468,557$ people [33]. A design matrix was formed after the extraction of the data, and the variables captured included the following, gender (sex), outcome of admission, principal diagnosis, location of patient (distance), occupation of patient, insurance of patient, ward admitted, age of patient, cost of treatment, date of admission and date of discharged (duration).

These variables were all coded as follows: gender $($ female $=f$, male $=m$ ), outcome of admission was categorized into three, either patient was discharged, absconded or died (discharged $=\mathrm{d}$, absconded $=\mathrm{a}$, death $=\mathrm{t}$ ), diagnosis of patients were into two categories (Typhoid Fever $=t$, Typhoid Perforation $=p$ ), location of patient was considered in terms of distance of the patient from his/her residence to the hospital. This was classified into two categories and coded as (less than 10 kilometers $=1$, greater or equal to 10 kilometers $=2$ ), insurance status of the patient was also categorized into two and coded as yes = insured, no $=$ not insured . Ward admitted was also coded as gynecology $=\mathrm{g}$, medical $=\mathrm{m}$, paediatrics $=\mathrm{p}$, surgical $=s$, maternity $=\mathrm{w}$. Age of patient was coded as under age (0-17years) $=1$, work force $(18-60$ years $)=2$, aged (61years and above) $=3$. Cost of treatment and duration were continuous variables.

\subsection{Concept of Generalized Linear Models and Model Building}

Generalized Linear Model (GLM) is considered to be a flexible generalization of ordinary linear regression which allows for response variables that have error distribution models other than a normal distribution. The GLM generalizes linear regression by allowing the linear model to be connected to the response variable through an interaction and by allowing the magnitude of the variations of each measurement to be a function of its predicted value. Generalized linear models was formulated by [34] as a way of uniting various other statistical models, including linear regression, logistic regression and Poisson regression. They proposed an iteratively reweighted least squares method for maximum likelihood estimation of the model parameters. Maximum-likelihood estimation remains popular and is the default method on many statistical computing packages. Other approaches, including Bayesian approaches and least squares fits to variance stabilized responses, have been developed. There are several assumptions such as normality, homoscedasticity and linearity. However, in Generalized Linear models, normality assumptions is usually dropped for exponential distributions, homoscedasticity is also dropped for the variance function, and the linear assumption is also dropped for the link function and then translate the nonlinearity into a function of linear relationships which we call linear predictors.

A generalized linear models is made up of a linear predictor

$$
Y=\beta_{0}+\beta_{1} x_{1}+\beta_{2} x_{2}+\ldots . .+\beta_{n} x_{n}
$$

and two functions

1. A link function describes how the mean,

$$
E\left(Y_{i}\right)=\mu_{i}
$$

Depends on the linear predictor

$$
g\left(\mu_{i}\right)=Y_{i}
$$


2. A variance function that describes how the variance,

$$
V\left(Y_{i}\right)
$$

depends on the mean

$$
V\left(Y_{i}\right)=\phi(\mu)
$$

Where the dispersion parameter $\phi$ is a constant [35].

The model of our study was given as

$$
\log Y=\beta_{0}+\beta_{1} x_{1}+\beta_{2} x_{2}+\ldots . .+\beta_{n} x_{n}
$$

The study looked at the Poisson distribution since a count data was considered. A negative binomial was subsequently fitted after the assumptions underlying the Poisson regression were not satisfied.

\subsubsection{Poisson distribution}

In analysing the data using Poisson distributions, it assumptions must be considered. And when such assumptions are violated then there will be a need to cure those violations in order to have an appropriate model. If either of these assumptions is violated, they can lead to extra variation, sometimes referred to as over dispersion. These assumptions are: The probability of observing a single event over a small interval is approximately proportional to the size of that interval, the probability of two events occurring in the same narrow interval is negligible, the probability of an event within a certain interval does not change over different intervals and the probability of an event in one interval is independent of the probability of an event in any other non-overlapping interval.

The number of days each patient stay at the hospital (in days) is recorded as count. As a consequence, the Poisson regression model is particularly appropriate for this type of response. The model is non-linear and describes the mean number of days. The distribution of the number of days using a Poisson model is of the form:

$$
\mathrm{P}(Y=y)=\frac{e^{-\lambda T}(\lambda T)^{y}}{y !}, \quad y=0,1,2, \ldots
$$

Where $y$ represents the observed number of days, $\lambda$ is a non-linear regression define as

$$
\lambda=e^{\beta x}>0
$$

The model matrix $X$ is a $(p \times 1)$ vector of explanatory variables and $\beta$ is a $(p \times 1)$ vector of regression parameters. The conditional mean

$$
E(y \mid x)=\lambda=e^{\beta^{\prime} x}
$$

The variance, (also called the heteroskedastic conditional variance) of the random variable is constrained to be equal to the mean i.e

$$
V(y \mid x)=\lambda
$$

In most practical situations such as ours, the estimates in (8), namely the $\beta$ 's are estimated by the method of maximum likelihood, although different methods are also available [36-39]. Because of the equidispersion assumption which, in most cases, is typical, our analysis added a fit of a more general specification model known as the Negative Binomial (NB) model. The mean of the Poisson distribution is $\lambda$. For the Poisson distribution, the variance, $\lambda$, is the same as the mean, so the standard deviation is $\sqrt{ } \lambda$.

\subsubsection{Negative binomial distribution}

This analysis is considered to be a fit of a more general specification model known as the Negative Binomial (NB) model. This model (at least one alternative of) has become the standard choice for basic statistical analysis of count data [37] especially among statisticians i.e., the so-called generalized linear model. [40] is among the first to use this as a tool for the analysis of count. A negative binomial experiment has the following properties: (a) The experiment consists of $x$ repeated trials (b) Each trial can result in just two possible outcomes. We call one of these outcomes a success and the other, a failure. (c) The probability of success, denoted by $P$, is the same on every trial.(d) The trials are independent from one another; the outcome on one trial does not affect the outcome on other trials.

\subsubsection{Mean of the negative binomial distribution}

If we define the mean of the negative binomial distribution as the average number of trials requi red to produce $r$ successes, then the mean is equal to: $\mu=\frac{r}{p}$ 
Where $\mu$ is the mean number of trials, $r$ is the number of successes, and $\mathrm{P}$ is the probability of a success on any given trial. The Negative Binomial probability distribution of $Y$ is

$$
\begin{array}{ll}
P\left(\frac{Y}{y}\right)=\left(\frac{(r)}{(r+\lambda)}\right) \mathrm{r} * \frac{\Gamma(\mathrm{r}+\lambda)}{\Gamma(\mathrm{y}+1) \Gamma \mathrm{r}} *\left(\frac{\lambda}{\lambda+\mathrm{r}}\right) y, & \mathrm{y}= \\
0,1 \ldots & (11)
\end{array}
$$

Where $\Gamma$ is the gamma function [41]. In this case, the mean of the negative binomial distribution is the same as that of the Poisson i.e.

$$
E\left(\frac{y}{x}\right)=\lambda
$$

But the variance is

$$
V\left(\frac{y}{x}\right)=\lambda+\frac{\lambda^{2}}{r}
$$

Where $r$ is the so-called dispersion parameter. The conditional variance of the Negative Binomial distribution exceeds the conditional mean. A general class of Negative Binomial is given in [42], and [43]. The variance function is

$$
\mu_{i}+\alpha \mu_{i} p
$$

The relationship in equation (13) is the variance of the negative binomial model, where $r$ is the dispersion parameter. A larger value of $r$ reduces the NB to Poisson. This is an establishment that clearly shows the correlation between the two formulas.

In classical linear model, $\varepsilon$ is considered to obey the normal distribution with the involvement of the identity link between $Y$ and $\mu$, the poisson regression uses the log link function to link the number of days spent in hospital. The negative Binomial uses the log-gamma link to establish the relationship in the negative binomial.

\section{RESULTS}

Interaction among the independent variables need to be checked regarding generalized linear models, in particular the Poisson model that was employed here. This was done through collinearity diagnostic test using the tolerance and the variance inflated factor (VIF) values to assess the interaction. From Table 1, it is seen that, the independent variables did not exhibit any interaction. This is evident as the VIF figures for each independent variable is within the reference value of $1<\mathrm{VIF}<5$. Also using the tolerance values from the Table 1 shows no interaction since each value was close to the reference figure of 1 .

Table 1. Collinearity diagnostic

\begin{tabular}{lll}
\hline Model variables & \multicolumn{2}{l}{ Collinearity statistics } \\
\cline { 2 - 3 } & Tolerance & VIF \\
\hline Cost of treatment & 0.788 & 1.268 \\
Gender of patient & 0.947 & 1.056 \\
Outcome of admission & 0.942 & 1.062 \\
Principal diagnosis & 0.922 & 1.085 \\
Location of patient & 0.881 & 1.135 \\
Occupation of patients & 0.864 & 1.158 \\
Insurance of patient & 0.971 & 1.029 \\
Ward admitted into & 0.754 & 1.327 \\
Age of patient & 0.942 & 1.062 \\
\hline
\end{tabular}

The Poisson regression was used first in modelling the length of stay of typhoid patients since it was a count data. Goodness of fit test revealed a lack of fit hence the Negative Binomial Regression provided a good fit (See Table 2). The log link function was used to link the independent variables age, gender, outcome, speciality, insurance, location, cost, diagnosis and occupation.

The Goodness-of-fit refers to the extent to which a fitted model will conform to the data used in the model construction. Table 2 shows the goodness of fit for both Poisson regression and the Negative Binomial. It can be observed that the model selection indicators for Negative Binomial are much smaller than the indicators for poisson, therefore among the two models Negative Binomial was best for the data set under this circumstance. The Chi-square and the deviance values for Poisson were high compared to the reference value, which is an indication for over dispersion. The chi-square and the deviance values were 0.386 and 0.427 respectively. These values clearly indicate that, the model is well fitted since they both have values less than one.

Table 4 shows the parameter estimates. For outcome of admission, the log of counts of days spent at the hospital is expected to decrease by 0.881 for every discharged case at the hospital holding all other significant predictors in the model constant. For cost of treatment, the expected log of counts of patient's days will increase by 0.001 for each 1 Ghana cedi increase in the cost of treatment of Typhoid patients holding all other significant predictors in 
the model constant. The log of counts of patients stay at the hospital whose residential location

was less than $10 \mathrm{~km}$ is expected to decrease by 0.264 for a unit distance increased by a $\mathrm{km}$

Table 2. Goodness of fit test for poisson regression and negative binomial

\begin{tabular}{lllllll}
\hline Parameters & \multicolumn{3}{c}{ Poisson } & \multicolumn{3}{c}{ Negative binomial } \\
\cline { 2 - 7 } & Value & DF & Sig. & Value & DF & Sig. \\
\hline Deviance & 1911.1 & 401 & 4.766 & 154.961 & 401 & 0.386 \\
Pearson chi-square & 2119.275 & 401 & 5.285 & 171.051 & 401 & 0.427 \\
Log likelihood & -1747.94 & & & -1338.87 & & \\
Akaike's Information Criterion (AIC) & 3529.884 & & & 2711.731 & & \\
Bayesian Information Criterion (BIC) & 3598.487 & & & 2780.334 & & \\
Consistence AIC & 3615.487 & & & 2797.334 & & \\
\hline
\end{tabular}

Table 3. Test of model effects for negative binomial

\begin{tabular}{llll}
\hline Source & Wald chi-square & DF & $P$-value \\
\hline Intercept $^{*}$ & 15.436 & 1 & 0.000 \\
Gender $^{*}$ & 0.366 & 1 & 0.545 \\
Outcome $^{*}$ & 20.578 & 2 & 0.000 \\
Diagnosis & 0.251 & 1 & 0.616 \\
Location $^{*}$ & 5.309 & 1 & 0.021 \\
Occupation & 2.808 & 4 & 0.590 \\
Insurance $_{\text {Speciality }}$ & 0.903 & 1 & 0.370 \\
Cost & 3.997 & 4 & 0.406 \\
Age & 96.653 & 1 & 0.000 \\
\hline & $0.128 \quad{ }^{*}$ Sig. $(P$-value $<0.05)$ & 0.721 \\
\hline
\end{tabular}

Table 4. Negative binomial parameter estimates

\begin{tabular}{|c|c|c|c|c|}
\hline Parameter & $B$ & Wald chi-square & DF & $P$-value \\
\hline Intercept $^{\star}$ & 1.665 & 4.255 & 1 & 0.039 \\
\hline Gender $=f$ & 0.069 & 0.366 & 1 & 0.545 \\
\hline Gender $=f$ & 0.000 & - & - & - \\
\hline Outcome $=a$ & -0.111 & 0.089 & 1 & 0.765 \\
\hline Outcome $=\mathrm{d}^{*}$ & -0.881 & 20.576 & 1 & 0.000 \\
\hline Outcome $=\mathrm{t}$ & 0.000 & - & - & - \\
\hline Diagnosis $=p$ & -0.078 & 0.251 & 1 & 0.616 \\
\hline Diagnosis $=\mathrm{t}$ & 0.000 & - & - & - \\
\hline Location $=1$ * & -0.264 & 5.309 & 1 & 0.021 \\
\hline Location=2 & 0.000 & - & - & - \\
\hline Occupation=a & -0.230 & 0.983 & 1 & 0.322 \\
\hline Occupation=h & -0.474 & 1.334 & 1 & 0.248 \\
\hline Occupation=s & -0.235 & 1.37 & 1 & 0.242 \\
\hline Occupation=t & -0.409 & 2.035 & 1 & 0.154 \\
\hline Occupation=u & 0.000 & - & - & - \\
\hline Insurance =n & 0.158 & 0.803 & 1 & 0.370 \\
\hline Insurance $=y$ & 0.000 & - & - & . \\
\hline Speciality $=\mathrm{g}$ & 0.198 & 0.047 & 1 & 0.829 \\
\hline Speciality $=\mathrm{m}$ & 0.196 & 0.061 & 1 & 0.905 \\
\hline Speciality $=p$ & 0.190 & 0.060 & 1 & 0.807 \\
\hline Speciality $=S$ & 0.464 & 0.358 & 1 & 0.550 \\
\hline Speciality $=w$ & 0.000 & - & - & - \\
\hline Cost $^{*}$ & 0.001 & 96.653 & 1 & 0.000 \\
\hline Age & -0.031 & 0.128 & 1 & 0.721 \\
\hline (Scale) & 1 & - & - & - \\
\hline (Negative Binomial) & 1 & - & - & - \\
\hline
\end{tabular}


whiles holding all other significant predictors in the model constant. This means that, the distance of typhoid patients contributes to how long they stay in the hospital. If the distance is $10 \mathrm{~km}$ or more, the likelihood of patient staying longer in the hospital is high and if the distance is less than $10 \mathrm{~km}$, the number of days a typhoid patient stay in the hospital is likely to reduce. The log of odds of patient days is expected to increase by 1.665 days if the distance (less than $10 \mathrm{~km}$ ) covered by patients, cost of treatment and death are all zero in the model.

It is also noted that, holding other variables constant, The log of counts of patients stay at the hospital whose occupation are into agriculture, handicraft, students and trade will reduce the expected length of stay by $0.23,0.47,0.24$ and 0.41 respectively. When a patient is admitted into gynecology Ward, the log of counts of patients stay at the hospital increases the expected length of stay by 0.20 . Medical ward, paediatrics ward and surgical ward increases the length of stay by $0.20,0.19$ and 0.46 respectively. For the age of patient, the expected log of counts of patient's stays will decrease by 0.31 . In general, it was observed from Table 4 that the variables that had significant effects $(P<0.05)$ were outcome of admission, location of patient and cost of treatment.

\section{DISCUSSION}

This is the first typhoid covariates study to the best of our knowledge for the Northern region of Ghana. Largely, these concept has been applied mostly to diarrhoea, cholera and malaria [43-45], and [46-48]. Although these studies have shown great potential in identifying the covariates for this disease, no study has been found in the literature that applied the same analytical tool to the study of length of stay of typhoid patients in Ghana.

In common with previous findings [5] and [49], we found that the under age group of $0-17$ years recorded the highest cases of typhoid. This confirms that the rate of infection is highest in young children placing more emphasis on vaccination policy [50]. Interestingly, we noticed that typhoid was evident in all age groups, and disproportionately affects both sex of the population.

In the Tamale metropolis of Ghana, the male population is more exposed for working and other purposes than females, which may explain the higher infection rates obtained for the males in the population [51]. Other factors such as location (that is either rural or urban) and cost of treatment may also be attributed to the disproportionate number of cases in the population [52]. Further study is therefore needed to determine the underlying risk factors of the disease for preventive measures to be put in place. The mean and median age of the cases was found to be 17 and 14 respectively, which contrasts earlier findings in Dhaka [14]. However it is similar to the results of studies from Pakistan, Indonesia and India [26,28-29]. A distinct seasonal variation was found with almost half $(45 \%)$ of the reported cases found to have occurred during the raining season. This is contrasting to the finding of a prospective community-based study [5] but supports other results $[28,49]$.

\section{CONCLUSIONS}

Typhoid fever is an acute illness associated with fever caused by Salmonella typhi bacteria. It can also be caused by Salmonella paratyphi. Generalized linear model was used to analyse the data. Both poisson and Negative Binomial Distributions were employed. It was noted after both analysis that, Negative Binomial was appropriate for the data. The test of the model effects indicated the variables that were significant. It shows that, the outcome of admission, location of patients and the costs of treatment were statistically significant $(P<0.05)$ in contributing to the length of stay of typhoid patients. The estimates of the parameters also showed the contributions of each variable in the work. It was realised that, a unit change in cost of treatment will increase the length of stay by $0.1 \%$ holding other variable constant. It was noted that, for keeping other variables constant, the outcome of admission (discharged) will reduce the expected length of stay by $88.1 \%$. It can also be seen that, holding other variables constant, the location of patient will reduce the expected length of stay by $26 \%$.

\section{CONSENT}

The data used did not require any permission from the patients since the identities of the patients was not in known and therefore not applicable here.

\section{ETHICAL APPROVAL}

It is not applicable. 


\section{COMPETING INTERESTS}

Authors have declared that no competing interests exist.

\section{REFERENCES}

1. Myron ML, Plotkin SA, Orenstein WA, Picazo JJ. Vacunas frente a la fiebre tioidea. Editors. Vacunas. $4^{\text {th }}$ ed. Madrid: Editorial Médica AWWE. 2007;1099-136.

2. Kanungo S, Dutta S, Sur D. Epidemiology of typhoid and paratyphoid fever in India. $J$ Infect Dev Ctries. 2008;26:454-460.

3. Anna E. Newton, Janell A. Routh, Barbara E. Mahon. Typhoid and paratyphoid fever. Center for Disease Control and Prevention CDC; 2008.

Available:http://www.cdc.gov/ncidod/dbmd/ diseaseinfo/TyphoidFever g.html

4. Bhan M, Bahl R, Bhatnagar S. Typhoid and paratyphoid fever. Lancet. 2005;749762.

5. Naheed A, Ram PK, Brooks WA, Hossain MA, Parsons MB, et al. Burden of typhoid and paratyphoid fever in a densely populated urban community, Dhaka, Bangladesh. Int J Infect Dis. 2010;14S3: e93-e99 .

6. Cameron C, Trivedi P. Regression analysis of count data. Cambridge University Press. New York; 1998.

7. WHO Epidemic and Pandemic Alert and Response [consulted 3/01/2016]. Avalaible:http://www.who.int/csr/don/2005 01 19/en/index.html

8. Mathura KC, Gurubacharya DL, Shrestha A, Pant S, Basnet P, Karki DB. Clinical profile of typhoid patients. Kathmandu Univ Med J. 2003;1:135-7.

9. Germanier R, Fuer E. Isolation an characterization of gal $E$ mutant Ty21a of Salmonella typhi: A candidate strain for A live oral typhoid vaccine. J Infect Dis. 1975;141:553-8.

10. Tagliabue A, Villa L, De Magistris MT, Romano M, Silvestris S, Boraschi D, et al. Iga-driven $\mathrm{T}$ cell-mediated anti-bacterial immunity in man after live oral Ty21a vaccine. J Immunol. 1986;137:1504-10.

11. Levine MM, Ferrecio C, Black RE, Lagos RS, Martin O, Blackwelder WC. Ty21a live oral typhoid vaccine and prevention of paratyphoid fever caused by Salmonella enterica serovar paratyphi B. Clin Infect Dis. $2007 ; 45: 24-8$.
12. Cook FJ, Day M, Wain J, Ward LR, Threlfall EJ. Cases of typhoid fever imported into England, Scotland and Wales. Trans R Soc Trop Med Hyg. 2007; 101:398-404.

13. Todd EC. Costs of acute bacterial foodborne disease in Canada and the United States. Int J Food Microbiol. 1989; 9:313-26.

14. Ram PK, Naheed A, Brooks WA, Hossain MA, Mintz ED, et al. Risk factors for typhoid fever in a Slum in Dhaka, Bangladesh. Epidemiol Infect. 2007;135: 458-465.

15. Crump JA, Luby SP, Mintz ED. The global burden of typhoid fever. Bull World Health Organ. 2004;82:346-353.

16. World Health Organization. Typhoid Fever. Geneva, Fact Sheet No. 1997;149.

17. Kothari A, Pruthi A, Chugh TD. The burden of enteric fever. J Infect Dev Ctries. 2008;24:253-259.

18. Sharma PK, Ramakrishnan R, Hutin Y, Manickam P, Gupte MD. Risk factors for typhoid in Darjeeling, West Bengal, India: Evidence for Practical Action. Trop Med Int Health. 2009;146:696-702.

19. Luby SP, Faizan MK, Fisher-Hoch SP, Syed A, Mintz ED, et al. Risk factors for typhoid fever in an epidemic setting, Karachi, Pakistan. Epidemiol Infect. 1998; 120(2):129-138.

20. Velema JP, van Wijnen G, Bult $P$, van Naerssen T, Jota S. Typhoid fever in Ujung Pandang, Indonesia- high risk groups and high-risk behaviours. Trop Med Int Health. 1997;211:1088-1094.

21. Black RE, Cisneros L, Levine MM, Banfi A, Lobos $\mathrm{H}$, et al. Case-control study to identify risk factors for paediatric endemic typhoid fever in Santiago, Chile. Bull World Health Organ. 1985;635:899-904.

22. Kelly-Hope LA, Alonso WJ, Theim VD, Anh DD, Canh DG, et al. Geographical distribution and risk factors associated with enteric diseases in Vietnam. Am J Trop Med Hyg. 2007;764:706-712.

23. Gasem $\mathrm{MH}$, Dolamans WM, Keuter MM, Djokomoeljanto RR. Poor food hygiene and housing as risk factors for typhoid fever in Semarang, Indonesia. Trop Med Int Health. 2001;66:484-490.

24. Mermin JH, Villar R, Carpenter J, Roberts $L$, Samaridden $A$, et al. $A$ massive epidemic of multidrug-resistant typhoid fever in Tajikistan associated with 
consumption of municipal water. J Infect Dis. 1999;1416-1422.

25. King CC, Chen CJ, You SL, Chuang YC, Huang $\mathrm{HH}$, et al. Community-wide epidemiological investigation of a typhoid outbreak in a rural township in Taiwan, Republic of China. Int J Epidemiol. 1989; 181:254-260.

26. Karkey A, Arjyal A, Anders KL, Boni MF, Dongol $S$, et al. The burden and characteristics of enteric fever at a healthcare facility in a densely populated area of Kathmandu. PloS One. 2010;511: e13988.

27. Tran $\mathrm{HH}$, Bjune $\mathrm{G}$, Nguyen $\mathrm{BM}$, Rottingen JA, Grais RF, Guerin PJ. Risk factors associated with typhoid fever in Son La Province, Northern Vietnam. Trans R Soc Trop Med Hyg. 2005;99:819-826.

28. Sur D, Ali M, Seidlein LV, Manna B, Deen $\mathrm{JL}$, et al. Comparisons of predictors for typhoid and paratyphoid fever in Kolkata, India. BMC Public Health. 2007;7:289.

29. Vollaard AM, Ali S, van Asten HAGH, Widjaja S, Visser LG, et al. Risk factors for typhoid and paratyphoid fever in Jakarta. JAMA. 2004;29121:2607-2615.

30. Whitaker JA, Franco-Pardes C, del Rio C, Edupuganti C. Rethinking typhoid fever vaccines: Implications for travelers and people living in highly endemic areas. J Travel Med. 2009;161:46-52.

31. Wang LX, Li XJ, Fang LQ, Wang DC, Cao $W C$, et al. Association between the incidence of typhoid and paratyphoid fever and meteorological variables in Guizhou, China. Chinese Med J. 2012;1253:455460.

32. Marks F, Adu-Sarkodie $Y$, Frank $H$, Nimako S, Samuel E, et al. Typhoid fever among children, Ghana. Emerg Infect Dis. 2010;16(11):1796-1797.

33. Ghana Statistical Service. Population Census, Ghana, a Publication of the Ghana Statistical Service; Sakoa Press Limited; 2010.

34. Nelder JA, Wedderburn RWM. Generalized linear models. Journal of the Royal Statistical Society. Series A (General). 1972;135(3):370-384.

35. Turner GM. A comparison of the limits to growth with 30 years of reality. Sciencedomain. 2008;18(3):397-411.

36. Hilbe JM, Greene W. Count response regression models. Handbook of Statistics. 2008;27:210-252.
37. Greene W. Functional forms of the negative binomial model for count data. Economic Letters. 2008;99:585-590.

38. Hilbe J. Log Negative Binomial Regression Using the GENMOD Procedure. In Proceedings of the Nineteenth Annual SAS Users Group International Conference, Cary, NC: SAS Institute Inc; 1994.

39. Wooldridge JM. Cluster-sample methods in applied econometrics: An Extended Analysis, Department of Economic, Michigan State University, East Lansing MI. 2003;48824-1038.

40. Anscombe FJ. The statistical analysis of insect counts based on the negative binomial distribution. Biometrics. 1949; 165-173.

41. Kiebel SJ, Holmes AP. The general linear model. The general linear model. In Frackowiak RSJ, Friston KJ, Frith C, Dolan R, Friston KJ, Price CJ, Zeki S, Ashburner $J$, Penny WD, Editors. Human Brain Function. Academic Press, 2nd Edition; 2003.

42. Cameron C, Trivedi P. Regression analysis of count data. Cambridge University Press. New York; 1998.

43. Haque U, Scott LM, Hashizume M, Fisher $E$, Haque $R$, et al. Modelling malaria treatment practices in Bangladesh using spatial statistics. Malar J. 2012;11:63.

44. Loth L, Gilbert M, Osmani MG, Kalam AM, Xiao X. Risk factors and clusters of highly pathogenic avian influenza H5N1 Outbreaks in Bangladesh; 2010.

45. Ali M, Emch M, Donnay JP, Yunus M, Sack RB. The spatial epidemiology of cholera in an endemic area of Bangladesh. Soc Sci Med. 2002a;55(6):1015-1024.

46. Ali $M$, Emch $M$, Donnay JP, Yunus $M$, Sack RB. Identifying environmental risk factors for endemic cholera: A raster GIS approach. Health Place. 2002b;8(3):201210.

47. Emch M. Relationships between flood control, Kala-Azar, and diarrheal disease in Bangladesh. Environ Plan A. 2000;32: 1051-1063.

48. Emch M, Ali M. Spatial and temporal patterns of diarrheal disease in Matlab, Bangladesh. Environ Plan A. 2001;33: 339-350.

49. Saha SK, Baqui AH, Abdullah H, Hanif M, Darmstadt GL, et al. Typhoid fever in Bangladesh: Implications for vaccination 
policy. Ped Infect Dis J. 2001;20(5):521524.

50. Nagashetty K, Channappa ST, Gaddad SM. Antimicrobial susceptibility of Salmonella typhi in India. J Infect Dev Ctries. 2010;42:070-073.

51. Morris JG Jr, Ferreccio C, Garcia J, Lobos $H$, Black RE, et al. Typhoid fever in Santiago, Chile: A study of household contacts of paediatric patients. Am J Trop Med Hyg. 1984;33(6):1198-1202.

52. Ochiai RL, Acosta CJ, Danovaro-Holliday MC, Baiqing D, Bhattacharya SK, et al. A study of typhoid fever in Five Asian Countries: Disease burden and implications for controls. Bull World Health Organ. 2008;86(4):260-268.

(c) 2016 Latif et al.; This is an Open Access article distributed under the terms of the Creative Commons Attribution License (http://creativecommons.org/licenses/by/4.0), which permits unrestricted use, distribution, and reproduction in any medium, provided the original work is properly cited.

Peer-review history:

The peer review history for this paper can be accessed here:

http://sciencedomain.org/review-history/16673 